\title{
Riscos ocupacionais na sala de vacinação e suas implicações à saúde do trabalhador de enfermagem
}

\author{
Occupational risks in the vaccination room and its implications for the health of the nursing workers \\ Riesgos laborales en la sala de vacunación y sus implicaciones para la salud del trabajador de enfermería
}

\author{
Elizabeth Camacho Fonsecal; Kayo Henrique Jardel Feitosa Sousa"'; Flaviana Pereira Bastos Nascimento"li; \\ Gisele Massante Peixoto Tracera ${ }^{\prime v}$; Katerine Moraes dos Santos"v; Regina Célia Gollner Zeitoune ${ }^{v l}$
}

\begin{abstract}
RESUMO
Objetivo: analisar a associação entre os riscos ocupacionais e os danos relacionados ao trabalho de enfermagem em sala de vacinação. Método: estudo transversal analítico realizado em salas de vacinação de unidades de atenção primária à saúde entre junho e julho de 2017, com 171 trabalhadores de enfermagem. Utilizou-se um instrumento com informações sobre dados sociodemográficos, laborais e riscos ocupacionais e a Escala de Avaliação dos Danos Relacionados ao Trabalho. Estudo aprovado pelo Comitê de Ética em Pesquisa. Resultados: a exposição ocupacional aos riscos físico e ergonômico esteve associada a todas as formas de adoecimento investigadas, enquanto que a exposição ao risco mecânico às formas de adoecimento relacionadas aos danos físicos e psicológicos. A exposição ao risco químico associou-se ao adoecimento físico. Conclusão: as condições de trabalho a que os profissionais da enfermagem são expostos nas salas de vacinação, expressadas em riscos ocupacionais, são associadas a danos à sua saúde.
\end{abstract}

Descritores: Doenças Ocupacionais; Saúde do Trabalhador; Enfermagem; Vacinação.

\section{ABSTRACT}

Objective: to analyze the association between occupational risks and damages related to nursing work in the vaccination room Method: analytical cross-sectional study conducted in the vaccination rooms of primary health care units in the city of Rio de Janeiro between June and July 2017, with 171 nursing workers. An instrument was used with information on sociodemographic, occupational and occupational risk data and the Work-Related Damage Assessment Scale. The study was approved by the research ethics committee. Results: occupational exposure to physical and ergonomic risk were associated with all forms of illness investigated, while exposure to mechanical risk to forms of illness related to Physical and Psychological Damage Exposure to chemical risk was associated to physical illness. Conclusion: the working conditions to which nursing professionals are exposed in vaccination room, expressed in occupational risks, negatively affect their health.

Descriptors: Occupational Diseases; Occupational Health; Nursing; Vaccination.

\section{RESUMEN}

Objetivo: analizar la asociación entre riesgos laborales y daños relacionados con el trabajo de enfermería en la sala de vacunación. Método: estudio transversal analítico realizado en las salas de vacunación de las unidades de atención primaria de salud de la ciudad de Río de Janeiro entre junio y julio de 2017, con 171 trabajadores de enfermería. Se utilizó un instrumento con información sobre datos sociodemográficos, laborales y de riesgos laborales y la Escala de evaluación de daños relacionados con el trabajo. El estudio fue aprobado por el comité de ética de investigación. Resultados: la exposición ocupacional al riesgo físico y ergonómico se asoció con todas las formas de enfermedad investigadas, mientras que la exposición al riesgo mecánico a las formas de enfermedad relacionadas con el daño físico y psicológico La exposición al riesgo químico se asoció a la enfermedad física. Conclusión: las condiciones de trabajo a las que están expuestos los profesionales de enfermería en la sala de vacunación, expresados en riesgos laborales, afectan negativamente su salud.

Descriptores: Enfermedades Profesionales; Salud Ocupacional; Enfermería; Vacunación.

\section{INTRODUÇÃO}

O trabalho pode ser um potencializador da qualidade de vida, na medida em que gera satisfação, favorecendo autoestima, equilíbrio emocional e reconhecimento social e financeiro e, por outro lado, pode ser origem de desgaste da saúde pela própria atividade realizada e o ambiente em que se desenvolve ${ }^{1}$. Observa-se que, na maioria das vezes, o ambiente de trabalho é dotado de riscos ocupacionais que podem provocar danos à saúde e à integridade física do trabalhador devido à sua natureza, suscetibilidade, intensidade, tempo de exposição e concentração, contribuindo para a ocorrência de acidentes de trabalho, erros de procedimentos e doenças ocupacionais².

'Enfermeira. Mestre. Professora na Fundação de Apoio à Escola Técnica do Estado do Rio de Janeiro. Brasil. E-mail: bethbele@gmail.com ORCID https://orcid.org/00000002-8138-6253

"Enfermeiro. Mestre. Doutorando em Enfermagem. Universidade Federal do Rio de Janeiro. Brasil. E-mail: kayohenriquejardel@hotmail.com ORCID https://orcid.org/0000-0002-0901-7752

I"Enfermeira. Mestranda em Enfermagem. Universidade Federal do Rio de Janeiro. Brasil. E-mail: flavi93nascimento@gmail.com ORCID https://orcid.org/0000-0001-7766-5463 IVEnfermeira. Mestre. Doutoranda em Enfermagem. Universidade Federal do Rio de Janeiro. Assistencial no Instituto de Atenção à Saúde São Francisco de Assis e na Universidade do Estado do Rio de Janeiro, Policlínica Piquet Carneiro. Brasil. E-mail: mtracera@gmail.com ORCID https://orcid.org/0000-0001-9896-9191

${ }^{\vee}$ Enfermeira. Mestre. Doutoranda em Enfermagem. Universidade Federal do Rio de Janeiro. Brasil. Assistencial no Instituto de Atenção à Saúde São Francisco de Assis e na Universidade do Estado do Rio de Janeiro, Policlínica Piquet Carneiro. Brasil. E-mail: katerinegm@gmail.com. ORCID https://orcid.org/0000-0002-2064-5207 VIEnfermeira. Doutora. Professora Titular. Universidade Federal do Rio de Janeiro. Brasil. E-mail: regina.zeitoune@gmail.com ORCID https://orcid.org/0000-0002-0948-5214 
Riscos ocupacionais, numa perspectiva mais inovadora, sustentada pela legislação brasileira, são compreendidos como a probabilidade de algum elemento ou circunstância, presente no ambiente ou no processo de trabalho, oferecer danos à saúde, seja por doença, acidente ou sofrimento ao trabalhador ${ }^{3}$. Esses riscos classificam-se em: físicos, químicos, biológicos, ergonômicos e psicossociais, mecânicos e de acidentes ${ }^{4}$.

Estudos $^{5-7}$ evidenciaram que os profissionais de saúde, devido às atividades inerentes a sua profissão, muitas vezes estão expostos a variados riscos ocupacionais. Dentre as categorias profissionais do setor saúde, os trabalhadores de enfermagem, por permanecerem frequentemente em contato direto com os clientes, são apontados como a categoria de maior exposição ${ }^{8,9}$.

Investigações que têm como foco os riscos ocupacionais entre trabalhadores de enfermagem predominam nas modalidades de atenção à saúde de média e alta complexidade. Entretanto, nos diferentes cenários laborais da enfermagem, os trabalhadores estão expostos a diversos fatores de risco e cargas de trabalho, capazes de comprometer a saúde desses profissionais ${ }^{3}$.

Nessa perspectiva, na Atenção Primária à Saúde (APS) também estão presentes os riscos ocupacionais, mas apresentando fatores de risco diferenciados ${ }^{5}$. No contexto da APS, dentre os itens elementares na estrutura, necessários para ofertar ações básicas, encontra-se a Sala de Vacinação $(\mathrm{SV})^{10}$, cenário de pesquisa desta investigação científica.

No Brasil, diferentemente de outros países, há na rede pública de saúde o Programa Nacional de Imunização (PNI), que se desenvolve por meio das SV, áreas destinadas exclusivamente à administração dos imunobiológicos ${ }^{11}$. O processo de trabalho nesse local é dinâmico e complexo em virtude da necessidade constante de atualizar conhecimentos sobre vacinação, confirmados pelas várias mudanças no calendário vacinal, com incorporação de novas vacinas, alterações de faixas etárias recomendadas para determinados imunobiológicos, modificando constantemente as recomendações ${ }^{12}$.

Apesar de haver o reconhecimento dos riscos e prejuízos à saúde do trabalhador relacionados a esse ambiente laboral, ainda existem poucas produções científicas - tanto no Brasil como no exterior - acerca dessa temática ${ }^{13}$. No cenário internacional, a exiguidade de publicações científicas pode ser justificada pela ausência de SV ou modalidade parecida, em contraponto com a realidade brasileira. Diante da complexidade do trabalho em SV, destaca-se a importância de pesquisas que abordem os riscos ocupacionais nesse contexto de trabalho de domínio exclusivo da enfermagem.

Estudo multicêntrico ${ }^{14}$ realizado com técnicos de enfermagem atuantes em unidades de APS nas regiões Sul, Norte e Centro-Oeste do Brasil, identificou aspectos que aumentam as cargas de trabalho para esses profissionais, tais como baixa remuneração mensal, falta de recursos materiais para assistência, sobrecarga de trabalho, sofrimento físico, relacionamento interpessoal e escassez de recursos humanos.

Nesse sentido, profissionais da APS atuantes em um município no Rio Grande do Sul avaliaram, como grave risco para adoecimento, o quantitativo de recursos humanos para a realização das tarefas, bem como as condições de trabalho, que foram avaliadas críticas para esse risco ${ }^{15}$.

Por estar inserida no contexto de trabalho da APS, a realidade da SV se assemelha aos dados apresentados anteriormente. Assim, o interesse na temática é por acreditar que os riscos ocupacionais também perpassam pelo ambiente laboral das SV, os quais de modo direto podem interferir negativamente no processo saúde-doença dos trabalhadores de enfermagem do setor. Dessa forma, este estudo vem contribuir com a produção científica no que tange aos riscos ocupacionais no ambiente de trabalho das SV da APS, contrapondo-se à temática geralmente abordada que focaliza o ambiente hospitalar.

Diante do exposto, o estudo teve como objetivo analisar a associação entre os riscos ocupacionais e os danos relacionados ao trabalho de enfermagem em sala de vacinação.

\section{MÉTODO}

Trata-se de um estudo transversal analítico, realizado nas SV das unidades de APS de áreas programáticas, no município do Rio de Janeiro.

Para a amostragem, adotou-se como critério de inclusão ser trabalhador de enfermagem atuante em SV; quanto aos critérios de exclusão, foram: afastamento por licença especial, licença médica não relacionada a doenças ocupacionais ou acidentes de trabalho e estar em férias na ocasião da coleta de dados. A população-alvo foi de 196 trabalhadores de enfermagem; destes, dois participaram do pré-teste (dados não considerados nas análises), que, somados a oito recusas, contabilizaram 10 perdas, além de 15 exclusões de acordo com os critérios pré-estabelecidos. A amostra foi composta por 23 enfermeiros, 115 técnicos de enfermagem e 33 auxiliares de enfermagem, totalizando 171 participantes, que representa uma taxa de adesão de $87,2 \%$. 
A coleta de dados ocorreu entre os meses de junho e julho de 2017 , tendo sido realizada pela pesquisadora principal. Os trabalhadores que atenderam aos critérios de inclusão foram individualmente contatados no local de trabalho. A pesquisadora disponibilizou ao trabalhador o instrumento de coleta de dados autoaplicável em um envelope não identificado. Nos casos em que o trabalhador não estivesse na unidade por quaisquer motivos, ele era contatado para outro encontro.

No instrumento continham informações referentes aos dados sociodemográficos, laborais e riscos ocupacionais, de elaboração própria, com questões objetivas e opções para registro dos riscos ocupacionais existentes referidos pelos trabalhadores no contexto das SV. Para avaliar os danos relacionados ao trabalho, foi utilizada a Escala de Avaliação dos Danos Relacionados ao Trabalho (EADRT), que faz parte do Inventário sobre o Trabalho e Riscos de Adoecimento (ITRA).

O ITRA mensura as distintas e interdependentes modalidades de representações dos respondentes, relativas ao mundo do trabalho. Foi criado e validado por Mendes e Ferreira, em 2003, com 5.437 trabalhadores de empresas públicas federais do Distrito Federal. O ITRA já se encontra na terceira versão, a qual foi aplicada nesta pesquisa ${ }^{16}$.

A EADRT é uma escala do tipo Likert de sete pontos, composta por três fatores: Danos Físicos, Danos Sociais e Danos Psicológicos, com eigenvalues de 1,5, variância de 50,09\% e correlações acima de 0,30. O fator Danos Físicos, definido como dores no corpo e distúrbios biológicos, apresenta 12 itens. O fator Danos Psicológicos, definido por sentimentos negativos em relação a si mesmo e à vida em geral, é composto por dez itens. O fator Danos Sociais contém sete itens referentes ao isolamento e dificuldades nas relações familiares e sociais ${ }^{16}$.

Os resultados são classificados em quatro níveis, a saber: acima de 4,1 = avaliação mais negativa, presença de doenças ocupacionais; entre 3,1 e 4,0 = avaliação moderada para frequente, grave; entre 2,0 e 3,0 = avaliação moderada, crítico; e abaixo de 1,9 = avaliação mais positiva, suportável ${ }^{16}$.

Os itens dispostos na escala representam situações pertinentes à saúde, e a sua aparição e repetição, em um nível moderado, retrata adoecimento. Neste estudo, optou-se por reagrupar essa avaliação em não adoecimento (escore igual ou inferior a 1,9) e adoecimento (escore superior a 1,9), pautando-se em estudo anterior ${ }^{17}$, com o objetivo de maximizar as diferenças entre grupos.

Para a avaliação dos riscos ocupacionais, calculou-se a média aritmética das repetições, utilizando-a como ponte de discriminação das categorias, a saber: sim (quando risco presente, quantidade de itens igual ou maior que a média aritmética) e não (sem risco, quando quantidade de itens menor que a média aritmética). Para os riscos ocupacionais, agruparam-se os itens em: físicos, biológicos, químicos, mecânicos e ergonômicos, com médias aritméticas, 02, 08, 08, 02 e 08, respectivamente.

Os dados foram digitados, organizados, processados e analisados estatisticamente com o auxílio do programa Statistical Package for the Social Sciences (SPSS), versão 21.0. As variáveis relacionadas aos riscos ocupacionais e ao adoecimento foram descritas por meio de frequência absoluta e relativa. As associações entre os riscos ocupacionais e o adoecimento do trabalhador nos três fatores (Danos Físicos, Danos Psicológicos e Danos Sociais) foram examinadas mediante o teste qui-quadrado, adotando-se $5 \%$ como nível de significância.

Foram obedecidas, em todas as etapas do estudo, as exigências da Resolução n. 466/2012, do Conselho Nacional de Saúde, que trata de pesquisas com seres humanos, obtendo Parecer n. 1.988.482, do Comitê de Ética em Pesquisa. Todos os participantes do presente estudo leram, assinaram e receberam uma via do Termo de Consentimento Livre e Esclarecido.

\section{RESULTADOS}

Dentre os indivíduos pesquisados, a maioria era técnico de enfermagem $(67,2 \%, n=115)$, do sexo feminino $(90,1 \%$, $n=154)$, não vivia com companheiro $(52,0 \%, n=89)$, tinha filhos $(67,3 \%, n=115)$ e cursou até o ensino médio $(71,3 \%$, $\mathrm{n}=122)$, possuía tempo de atuação menor que três anos $(51,5 \%, n=88)$, tinha apenas um vínculo empregatício $(79,5 \%$, $n=136)$ e recebeu capacitação para atuar na SV $(69,6 \%, n=119)$, enquanto $21,6 \%(n=37)$ já haviam se envolvido em algum tipo de acidente de trabalho. A média de idade da amostra foi de 41,77 anos.

Com base nos resultados apresentados na Tabela 1, verificou-se a predominância da avaliação suportável para todos os danos, sendo que na avaliação crítica predominou o fator Danos Físicos e, na grave, o fator Danos Psicológicos. Observou-se também o predomínio dos Danos Psicológicos na classificação doenças.

Considerando os riscos ocupacionais relacionados ao trabalho nas SV, identificou-se predominância do risco químico, seguido do risco biológico e do risco mecânico, conforme se observa na Tabela 2.

Os dados da Tabela 2 mostram ainda que a exposição ocupacional ao risco físico e ao ergonômico esteve associada a todas as formas de adoecimento investigadas, enquanto a exposição ao risco mecânico, às formas de adoecimento relacionadas aos Danos Físicos e Psicológicos, e a exposição ao risco químico, ao adoecimento físico. Nota-se que a exposição ao risco biológico não se mostrou associada a nenhuma das formas de adoecimento estudadas aqui. 
TABELA 1: Distribuição dos danos relacionados à saúde dos trabalhadores de enfermagem das salas de vacinação da cidade do Rio de Janeiro segundo a classificação dos fatores da EADRT. Rio de Janeiro, RJ, Brasil, 2017. $(n=171)$

\begin{tabular}{|c|c|c|c|c|c|c|c|c|}
\hline \multirow[t]{3}{*}{ Fator } & \multicolumn{8}{|c|}{ Classificação } \\
\hline & \multicolumn{2}{|c|}{ Suportável } & \multicolumn{2}{|c|}{ Crítico } & \multicolumn{2}{|c|}{ Grave } & \multicolumn{2}{|c|}{ Doenças } \\
\hline & $\mathbf{n}$ & $\%$ & $\mathbf{n}$ & $\%$ & $\mathbf{n}$ & $\%$ & $\mathbf{n}$ & $\%$ \\
\hline Danos Físicos & 129 & 75,4 & 40 & 23,4 & 02 & 1,2 & 00 & 0,0 \\
\hline Danos Psicológicos & 132 & 77,3 & 17 & 9,9 & 11 & 6,4 & 11 & 6,4 \\
\hline Danos Sociais & 155 & 90,6 & 13 & 7,6 & 01 & 0,6 & 02 & 1,2 \\
\hline
\end{tabular}

TABELA 2: Associação entre a exposição aos riscos ocupacionais e o adoecimento avaliado pela Escala de Avaliação de Danos Relacionados ao Trabalho. Rio de Janeiro, RJ, Brasil, 2017. $(n=171)$

\begin{tabular}{|c|c|c|c|c|c|c|c|c|c|c|}
\hline \multirow[t]{2}{*}{ RISCO } & \multirow[t]{2}{*}{$n(\%)$} & \multicolumn{2}{|c|}{$\begin{array}{c}\text { Adoecimento } \\
\text { Físico }\end{array}$} & \multirow[t]{2}{*}{$\begin{array}{c}p- \\
\text { value }\end{array}$} & \multicolumn{2}{|c|}{$\begin{array}{l}\text { Adoecimento } \\
\text { Psicológico }\end{array}$} & \multirow[t]{2}{*}{$\begin{array}{c}p- \\
\text { value }\end{array}$} & \multicolumn{2}{|c|}{$\begin{array}{c}\text { Adoecimento } \\
\text { Social }\end{array}$} & \multirow[t]{2}{*}{$\begin{array}{c}p- \\
\text { value }\end{array}$} \\
\hline & & $\begin{array}{l}\text { Não } \\
\text { n(\%) }\end{array}$ & $\begin{array}{l}\text { Sim } \\
n(\%)\end{array}$ & & $\begin{array}{l}\text { Não } \\
\mathrm{n}(\%)\end{array}$ & $\begin{array}{l}\text { Sim } \\
n(\%)\end{array}$ & & $\begin{array}{l}\text { Não } \\
n(\%)\end{array}$ & $\begin{array}{l}\text { Sim } \\
n(\%)\end{array}$ & \\
\hline Físico & & & & 0,006 & & & 0,033 & & & 0,045 \\
\hline Sim & $67(39,2)$ & $43(64,2)$ & $24(35,8)$ & & $46(68,7)$ & $21(31,3)$ & & $57(85,1)$ & $10(14,9)$ & \\
\hline Não & $104(60,8)$ & $86(82,7)$ & $18(17,3)$ & & $86(82,7)$ & $18(17,3)$ & & $98(94,2)$ & $06(5,8)$ & \\
\hline Biológico & & & & 0,118 & & & 0,958 & & & 0,126 \\
\hline Sim & $109(63,7)$ & $78(71,6)$ & $31(28,4)$ & & $84(77,1)$ & $25(22,9)$ & & $96(88,1)$ & $13(11,9)$ & \\
\hline Não & $62(36,3)$ & $51(82,3)$ & $11(17,7)$ & & $48(77,4)$ & $14(22,6)$ & & $59(95,2)$ & $03(4,8)$ & \\
\hline Químico & & & & 0,035 & & & 0,782 & & & 0,259 \\
\hline Sim & $130(76,0)$ & $93(71,5)$ & $37(28,5)$ & & $101(77,4)$ & $29(22,3)$ & & $\begin{array}{c}116(89, \\
2)\end{array}$ & $14(10,8)$ & \\
\hline Não & $41(24,0)$ & $36(87,8)$ & $05(12,2)$ & & $31(75,6)$ & $10(24,4)$ & & $39(95,1)$ & $02(4,9)$ & \\
\hline Mecânico & & & & 0,003 & & & 0,010 & & & 0,208 \\
\hline Sim & $92(53,8)$ & $61(66,3)$ & $31(33,7)$ & & $64(69,6)$ & $28(30,4)$ & & $81(88,0)$ & $11(12,0)$ & \\
\hline Não & $79(46,2)$ & $68(86,1)$ & $11(13,9)$ & & $68(86,1)$ & $11(13,9)$ & & $74(93,7)$ & $05(6,3)$ & \\
\hline Ergonômico & & & & $<0,001$ & & & $<0,001$ & & & 0,001 \\
\hline Sim & $85(49,7)$ & $53(62,4)$ & $32(37,6)$ & & $50(58,8)$ & $35(41,2)$ & & $71(83,5)$ & $14(16,5)$ & \\
\hline Não & $86(50,3)$ & $76(88,4)$ & $10(11,6)$ & & $82(95,3)$ & $04(4,7)$ & & $84(97,7)$ & $02(2,3)$ & \\
\hline
\end{tabular}

Dentre os riscos ocupacionais de maior exposição, destacou-se o risco químico relacionado aos aerossóis liberados pelas vacinas tríplice viral $(n=70)$, seguida de febre amarela $(n=60)$ e BCG $(n=45)$. Ainda com relação ao risco químico, na forma líquida, predominaram citações referentes a todas as vacinas ( $n=38)$, acompanhada de $B C G(n=24)$ e febre amarela $(n=22)$ (Tabela 3).

TABELA 3: Exposição ao risco químico relacionada às formas líquida e aerossóis liberados pelas vacinas, segundo a opinião dos trabalhadores de enfermagem. Rio de Janeiro, RJ, Brasil, 2017. $(n=171)$

\begin{tabular}{lcc}
\hline Vacina & Líquida & Aerossóis \\
\hline Todas & 38 & 04 \\
BCG & 24 & 45 \\
Febre amarela & 22 & 60 \\
Tríplice viral & 20 & 70 \\
Varicela & 01 & 11 \\
Pentavalente/DTP/dT & 05 & 05 \\
Tetraviral & 02 & 04 \\
Influenza & 07 & 03 \\
Anti-rábica & 01 & 02 \\
Rotavírus & 19 & - \\
VOP & 06 & - \\
Pneumocócica & 02 & - \\
Hepatite B & 04 & - \\
VIP & 01 & - \\
Diluídas & - & 01 \\
Total & $\mathbf{1 5 4}$ & $\mathbf{2 0 5}$
\end{tabular}




\section{DISCUSSÃO}

Neste estudo, os riscos ocupacionais do trabalho de enfermagem nas SV, destacados pelos participantes, foram predominantemente os riscos químico, biológico e mecânico. Tal resultado encontra-se em dissonância com a literatura, ${ }^{18}$ ao identificar que foram referidos, pela maioria dos trabalhadores de SV, apenas os riscos ergonômico e biológico. Por outro lado, ao estudar sobre gerenciamento dos riscos ocupacionais da enfermagem na APS ${ }^{5}$, evidenciouse que a maior preocupação dos trabalhadores foi com o risco biológico, resultante da manipulação de perfurocortantes e do contato com pacientes que têm doenças transmissíveis.

O risco químico esteve associado ao contato direto com as substâncias químicas presentes na composição dos imunobiológicos nas formas líquida e de aerossóis (aerolização) durante a sua diluição, aspiração e administração. Houve predominância de referência ao risco químico nas SV, corroborando com estudo de revisão que abordou a exposição dos trabalhadores da APS aos riscos químicos na preparação e administração de imunobiológicos ou de medicação, e no contato direto com os produtos para limpeza e desinfecção, como hipoclorito de sódio e o álcool ${ }^{19}$.

Em consonância com os dados encontrados, auxiliares de enfermagem de SV da zona urbana do Ceará relataram infecção com a vacina tríplice viral e $\mathrm{BCG}^{20}$. Destaque ainda para inoculação ocular e percutânea acidental durante o preparo e administração da vacina BCG sem a utilização de óculos e máscara. O Ministério da Saúde reconhece o risco de infecção ao alertar que, sendo a vacina BCG fechada a vácuo, "quando o ar entra bruscamente no interior da ampola, o liófilo pode ser expulso sob a forma de aerossóis e contaminar o ambiente"11:71.

Ressalta-se que a exposição constante às substâncias químicas sem a proteção adequada tende a propiciar problemas à saúde das pessoas. Ainda nessa linha, estudo ${ }^{5}$ sobre gerenciamento dos riscos ocupacionais da enfermagem na APS apontou que irritação em mucosas, região cutânea, trato respiratório e digestivo - proveniente da exposição a essas substâncias - foram mencionadas em todas as fichas de informação de segurança de produto químico. $\mathrm{Na}$ correlação entre as substâncias químicas e o risco de respingo, identificou-se que um pequeno número de profissionais apresentou algum prejuízo em consequência da manipulação dessas substâncias.

Nas SV são usados os imunobiológicos compostos por bacilos e vírus vivos e os que contêm microrganismos inativados, tendo, em suas composições, antibióticos e produtos químicos que conservam e aumentam a resposta imune dos imunobiológicos ${ }^{11}$. Nesta investigação, os resultados apontaram para uma exposição às composições químicas dos imunobiológicos. Vale ressaltar que a produção científica abrangendo a exposição dos profissionais à composição das vacinas ainda é escassa. Considerando a relevância do assunto na perspectiva da saúde do trabalhador, essa questão merece reflexão e aprofundamento. Nesse sentido, novas pesquisas sobre o assunto devem ser incentivadas.

Remetendo à exposição ao risco químico relacionado à composição da vacina na forma líquida, um quarto dos participantes declarou exposição a todas as vacinas, e aproximadamente $15 \%$ mencionaram a BCG, a febre amarela, a tríplice viral e a rotavírus. No que tange ao preparo dos imunobiológicos nas SV, destaca-se a atenção que o profissional deve ter para manter o equilíbrio das pressões dentro e fora do frasco ao diluir e aspirar a vacina. A falta de cuidado pode ocasionar a aerolização do imunobiológico, expondo o trabalhador às partículas suspensas no ambiente, as quais podem ser inaladas ou absorvidas pela pele do vacinador.

Dependendo da natureza, concentração ou intensidade e tempo de exposição às substâncias químicas existentes no contexto laboral, podem trazer prejuízos à saúde dos trabalhadores, como erupção cutânea nos clientes e nos trabalhadores que as contactaram ${ }^{21}$. A primeira condição para que elas provoquem algum dano é que entrem em contato ou penetrem o corpo através da pele (absorção dérmica), pela inalação (absorção pelos pulmões) ou ingestão (absorção pelo trato digestivo). Salienta-se que a via de exposição mais tóxica é a inalatória, seguida pela ingestão e absorção dérmica ${ }^{22}$.

Nesse contexto, torna-se importante a prevenção de exposição aos fármacos liberados no ar, no ambiente, na roupa, nos equipamentos e no local de trabalho. Reitera-se que o uso de Equipamentos de Proteção Individual (EPI) durante o manuseio dos fármacos é uma medida que pode minimizar a exposição ao risco ${ }^{21}$.

Sequencialmente, o risco biológico foi o segundo mais relatado pelos respondentes do estudo em tela. Estudos revelam que a SV, apesar de ser considerada um local com objetivo de prevenir o adoecimento, proporciona exposição contínua a riscos ocupacionais relacionados a resíduos contaminados, fluidos orgânicos e imunobiológicos constituídos de definidas classes de vírus e bactérias ${ }^{18,19}$.

Destaca-se que, nesse setor, além do manuseio e administração sucessiva de imunobiológicos, o trabalhador também realiza o teste do pezinho e o contato direto com o cliente sem conhecimento prévio do seu estado de saúde. Tais encargos expõem o profissional a riscos de infecção por material biológico, podendo entrar em contato com os vírus da Hepatite $B$, Hepatite $C$ e o vírus da imunodeficiência humana (HIV). Outrossim, a equipe de enfermagem, em 
todas as modalidades de assistência, é acometida frequentemente por acidentes com materiais perfurocortantes contaminados com sangue ${ }^{3,8}$.

Evidenciou-se, neste estudo, que os riscos mecânicos e de acidentes foram o terceiro risco mais citado pelos trabalhadores. Esse fato também deve ser contemplado, corroborando com outro estudo que identificou o risco mecânico nas SV, possuindo problemas críticos de organização em sua estrutura ${ }^{5}$, como espaços mal planejados e mobílias mal projetadas. No que tange a riscos mecânicos, estudos constataram que eles estão entre as principais causas de acidentes de trabalho em Unidades Básicas de Saúde (UBS ${ }^{23}$ e entre auxiliares e técnicos de enfermagem da Estratégia Saúde da Família (ESF) ${ }^{24}$.

Diante do exposto, infere-se que os riscos mecânicos estão inseridos no contexto da APS e, por conseguinte, nas SV. Assim, ficam evidentes os agravos à saúde do trabalhador, advindos da presença de risco mecânico e de acidente nesses serviços. Ressalta-se que pesquisas versando sobre os riscos mecânicos na SV ainda são incipientes ${ }^{5}$.

No que diz respeito à associação entre a exposição aos riscos e os danos à saúde, observou-se que tanto os riscos físicos como os ergonômicos tiveram relação com os três fatores de danos (físico, psicológico e social). Em vista disso, estudo $^{25}$ realizado em Taiwan encontrou uma associação significativa entre sintomas físicos e psicológicos, sendo estes ocasionados devido à exposição ao estresse e o desgaste no local de trabalho, pelo trabalho em turnos, a má postura e o descanso insuficiente. Outra pesquisa ${ }^{15}$, realizada no contexto da APS, identificou que profissionais consideram crítica a avaliação da organização do trabalho, sendo esse fator o principal determinante de sofrimento do trabalhador - com efeitos negativos à saúde -, devido às pressões de curto prazo, altas demandas, repetições de atividades, ritmo acelerado e outros.

Outro estudo ${ }^{26}$ com profissionais da ESF encontrou correlação negativa entre os fatores que compõem o contexto de trabalho e os domínios da qualidade de vida - físico, psicológico e social -, permitindo compreender que as condições de trabalho afetam negativamente a qualidade de vida dos profissionais da enfermagem. Destacando a exposição ao risco físico, estudo ${ }^{27}$ apontou que a ventilação insuficiente - que gera calor excessivo - foi considerada fator de desconforto para os profissionais durante o seu trabalho.

A exposição ao risco mecânico teve relação com os danos físico e psicológico. Ressalta-se que os profissionais consideram estar mais suscetíveis aos riscos de acidentes relacionados ao uso de máquinas no trabalho e exposição a materiais perfurocortantes ${ }^{27}$. Considerando que o risco químico se associou aos danos físicos, dados corroborados por estudo ${ }^{28}$, permite-nos refletir se tal risco se correlaciona com as diferentes substâncias utilizadas pelos profissionais de enfermagem, capazes de adentrar o corpo e causar alterações na saúde.

Pode-se perceber que o risco biológico não se associou aos danos à saúde dos profissionais na presente pesquisa - dado que requer aprofundamento em futuros estudos -, pois considera-se que existe um risco potencial de exposição a materiais biológicos em $90 \%$ dos procedimentos realizados pelos profissionais da saúde ${ }^{29}$, sendo a SV um serviço em que há essa exposição cotidianamente no trabalho da enfermagem.

Em contraponto aos dados desta pesquisa, ao analisar a situação de exposição de trabalhadores a agentes biológicos, um estudo ${ }^{29}$ identificou expressões psicológicas relacionadas ao desespero e ao medo referentes a acidentes, e que esses profissionais sentem-se vulneráveis ao realizar suas atividades. Destaca-se, portanto, a importância da gestão de biossegurança às práticas cotidianas, fortalecendo a prevenção de riscos pela melhoria das condições de trabalho ${ }^{30}$.

Dessa forma, com vistas à prevenção e/ou minimização dos riscos ocupacionais, deve-se criar no contexto laboral - dentre outras medidas, como educação permanente, recursos humanos adequados, equipamentos e mobiliários apropriados - espaços para reflexão coletiva entre os trabalhadores acerca do seu processo de trabalho.

Este estudo apresenta, como limitações, o próprio desenho metodológico, o qual inviabiliza a definição de causalidade e a subjetividade inerentes aos desfechos analisados, que podem ser influenciadas pelos estados dos indivíduos, somados ao processo de amostragem por conveniência, sem dúvida não suficiente para generalização dos achados aqui apresentados. Contudo, traz contribuições relevantes na medida em que oferece informações da avaliação dos danos à saúde que acometem os profissionais que atuam nas SV. Ademais, oportuniza a identificação dos riscos ocupacionais nesse ambiente, com destaque ao potencial inovador da investigação delinear um ambiente de domínio exclusivo da enfermagem, demonstrando associações significativas entre essas variáveis relacionadas ao trabalho.

\section{CONCLUSÃO}

Os danos à saúde que acometeram os profissionais que atuavam nas SV prevaleceram com avaliação crítica e grave nos fatores psicológicos e físicos, e avaliação doença, nos danos psicológicos. Acerca dos riscos ocupacionais deste trabalho, foram destacados predominantemente, pelos participantes, os riscos químico, biológico e mecânico. 
Foi possível identificar associações significativas entre os riscos ocupacionais e danos, demonstrando que esses riscos influenciam no desenvolvimento de problemas físicos, psicológicos e/ou sociais. Ao ob servar o risco químico, percebeu-se o predomínio da exposição ao risco químico na forma de aerossóis nas vacinas tríplice viral e febre amarela.

Assim, pode-se inferir que as condições de trabalho às quais os profissionais da enfermagem são expostos nas SV, - expressas em riscos ocupacionais - afetam negativamente a sua saúde. Portanto, faz-se necessário construir estratégias de educação permanente relacionadas aos riscos ocupacionais, visando a redução dos problemas que acometem a equipe de enfermagem.

\section{REFERÊNCIAS}

1. Rosado IVM, Russo GHA, Maia EMC. Generating health elicits illness? The contradictions of work performed in emergency care units of public hospitals. Ciênc. saúde coletiva (Online). [Internet], 2015 [cited 2019 Jan 06]; 20(10): 3021-32. DOI: https://doi.org/10.1590/1413-812320152010.13202014.

2. Ferreira AP, Grams MT, Erthal RMC, Girianelli VR, Oliveira MHB. Literature review onworking environment hazards relative to the working conditions and impact on workers' health. Rev Bras Med Trab. [Internet], 2018 [cited 2019 Dec 12]; 16(3): 360-70. DOI: http://dx.doi.org/10.5327/Z1679443520180267.

3. Loro MM, Zeitoune RCG, Guido LA, Silveira CR, Silva RM. Revealing risk situations in the context of nursing work at urgency and emergency services. Esc. Anna Nery Rev. Enferm. [Internet], 2016 [cited 2019 Jan 06]; 20(4): e20160086. Available from: https://www.scielo.br/pdf/ean/v20n4/1414-8145-ean-20-04-20160086.pdf.

4. Ministério da Saúde (BR). Tratamento, reabilitação, prevenção e fisiopatologia das LER/DORT. Brasília (DF): Ministério da Saúde; 2001. [cited 2019 Jan 06]. Available from: http://bvsms.saude.gov.br/bvs/publicacoes/ler_dort.pdf.

5. Arcanjo RVG, Chistovam BP, Braga ALS, Silvino ZR. Management of occupational risks of nursing in primary health care: a descriptive exploratory study. Rev. pesqui. cuid. fundam. (Online). 2018 [cited 2019 Dec 10]; 10(2): 351-57. DOI: http://dx.doi.org/10.9789/2175-5361.2018.v10i2.351-357.

6. Giurgiu DI, Jeoffrion C, Roland-Lévy C, Grasset B, Dessomme BK, Moret L, et al. Wellbeing and occupational risk perception among health care workers: a multicenter study in Morocco and France. J. Occup. Med. Toxicol. [Internet]. 2016 [cited 2019 Jan 06]; 11: 20. DOI: http://dx.doi.org/10.1186/s12995-016-0110-0.

7. Escobar MB, Rivera DCC, Duque MIO. Occupational context of nursing professionals in colombia. Rev. cuba. saludtrab. [Internet]. 2018 [cited 2019 Jun 26]; 19(1): 66-72. Available from: https://www.medigraphic.com/pdfs/revcubsaltra/cst2018/cst181k.pdf.

8. Loro MM, Zeitoune RCG, Guido LA, Silva RM, Kolankiewicz ACB. Occupational risks and health of nursing workers - seeking evidences. Rev. pesqui. cuid. fundam. (Online). 2014 [cited 2019 Jun 26]; 6(4): 1610-21. DOI: http://dx.doi.org/10.9789/21755361.2014.v6i4.1610-1621.

9. Santos PL, Gomes AC, Alves FF, Castelan E, Dib RV, Mercês MC, et al. Social representations of occupational accident risks. Rev. bras. promoç, saúde. [Internet]. 2018 [cited 2019 Dec 06]; 31(2): 1-10. DOI: http://dx.doi.org/10.5020/18061230.2018.7074.

10. Lima LD, Albuquerque MV, Scatena JHG. Quem governa e como se governam as regiões e redes de atenção à saúde no Brasil? Contribuições para o estudo da governança regional na saúde. Novos Caminhos. Pesquisa Política, Planejamento e Gestão das Regiões e Redes de Atenção à Saúde no Brasil (Região e Redes). [Internet] 2016 [cited 2019 Jun 26]. Available from: http://www.resbr.net.br/wp-content/uploads/2016/02/Novos-Caminhos-8.pdf.

11. Ministério da Saúde (BR). Secretaria de Vigilância em Saúde. Departamento de Vigilância das Doenças Transmissíveis. Manual de Normas e Procedimentos para Vacinação. Brasília (DF): Ministério da Saúde; 2014 [cited 2019 Jun 01]. Available from: http://bvsms.saude.gov.br/bvs/publicacoes/manual_procedimentos_vacinacao.pdf.

12. Martins JRT, Alexandre BGP, Oliveira VC, Viegas SMF. Permanent education in the vaccination room: what is the reality?. Rev. bras. enferm. (Online). 2018 [cited 2019 Dec 02]; 71(suppl 1): 668-76. DOI: http://dx.doi.org/10.1590/0034-7167-2017-0560.

13. Bastos RAA, Garrido GS, Almeida FCA, Pequeno GA, Farias JC, Bezerra CMB, et al. Immunization: occupational risks in nursing workers within the scope of the Family Health Strategy. Int Ach Med. [Internet]. 2017 [cited 2019 Jun 26]; 10(61): 1-7. DOI: http://dx.doi.org/10.3823/2331.

14. Scherer MDA, Oliveira NA, Pires DEP, Trindade LL, Gonçalves ASR, Vieira M. Increased workloads for nurse technicians in primary health care in brazil. Trab. educ. saúde. [Internet]. 2016 [cited 2019 Jun 26]; 14(suppl.1): 89-104. DOI: http://dx.doi.org/10.1590/1981-7746-sol00030.

15. Maissiat GS, Lautert L, Pai DD, Tavares JP. Work context, job satisfaction and suffering in primary health care. Rev. gaúch. enferm. [Internet]. 2015 [cited 2019 Jan 06]; 36(2): 42-9. DOI: http://dx.doi.org/10.1590/1983-1447.2015.02.51128.

16. Mendes AM, Ferreira MC. Inventário sobre Trabalho e Riscos de Adoecimento - ITRA: instrumento auxiliar de diagnóstico de indicadores críticos no trabalho. In: Psicodinâmica do Trabalho: teoria, método e pesquisas. Ana Magnólia Mendes (org.) São Paulo: Casa do Psicólogo; 2007.

17. Silva RM, Zeitoune RCG, Beck CLC, Martino MMF, Prestes FC. The effects of work on the health of nurses who work in clinical surgery departments at university hospitals. Rev. latinoam. enferm. (Online). [Internet]. 2016 [cited 2019 Jan 26]; 24:e2743. DOI: http://dx.doi.org/10.1590/1518-8345.0763.2743.

18. Giovelli G, Cardoso SMM, Fontana RT, Rodrigues FCP, Brum ZP. Nursing technicians' perceptions regarding the occupational risks in vaccination rooms. Cogitare enferm. [Internet]. 2014 [cited 2019 Jun 26]; 19(2): 354-60. DOI: http://dx.doi.org/10.5380/ce.v19i2.37006. 
19. Monteiro GR, Silva MES, Oliveira RC. Risk map as an instrument for the identification of occupational hazard: an integrative review of the literature. Rev. pesqui. cuid. fundam. (Online). 2015 [cited 2019 Jun 26]; 7(3):3076-92. Available from: http://www.seer.unirio.br/index.php/cuidadofundamental/article/view/3471/pdf_1674.

20. Feitosa LR, Feitosa JA, Coriolano MWL. Conhecimento e práticas do auxiliar de enfermagem em sala de imunização. Cogitare enferm. [Internet]. 2010 [cited 2019 Jun 07]; 15(4): 695-701. DOI: http://dx.doi.org/10.5380/ce.v15i4.20370.

21. National Institute for Occupational Safety and Health (NIOSH). Pocket guide to chemical hazards (NPG). 2004 [cited 2019 Jul 27]; (97-140). Available from: http://www.cdc.gov/niosh/npg/npg.html.

22. Organização Mundial da Saúde (OMS). Programa Internacional de Segurança Química. Substâncias químicas perigosas à saúde e ao ambiente. São Paulo (SP): Cultura Acadêmica; 2008 [cited 2019 Feb 26]. Available from:

1. https://www.unesp.br/pgr/manuais/subs_quimicas.pdf.

23. Medeiros AL, Costa MBS, Sousa MCJ, Rosenstock KIV. Gerenciamento de riscos e segurança no trabalho em unidades de saúde da família. Rev. bras. ciênc. saúde. [Internet]. 2013 [cited 2019 Mar 26]; 17(4): 341-8. Available from: http://periodicos.ufpb.br/index.php/rbcs/article/view/12677.

24. Ferraz L, Kessler M, Krauzer IM, Trindade LL, Silva OM. Family health strategy: occupational risks the technical and auxiliary nursing. Revista Recien. [Internet]. 2015 [cited 2019 Mar 08]; 5(13): 20-8. Available from: http://www.recien.com.br/index.php/Recien/article/view/91/159.

25. Chen MJ, Weng SS. Psychological symptoms among hospital nurses in Taiwan: a cross sectional study. BMC women health, [Internet]. 2017 [cited 2019 Mar 06]; 17: 101. DOI: http://dx.doi.org/10.1186/s12905-017-0460-5.

26. Marques ALN, Ferreira MBG, Duarte JMG, Costa NS, Haas VJ, Simões ALA. Quality of life and working context of nursing professionals of the Family Health Strategy. Rev. Rene. [Internet]. 2015 [cited 2019 Jun 26]; 16(5): 672-81. DOI: http://dx.doi.org/10.15253/2175-6783.2015000500008.

27. Lima MDP, Chaves BJP, Lima VS, Silva PE, Soares NSCS, Santos IBC. Occupational hazards in nursing professionals at materials and sterilization centers. Rev. cuid. [Internet]. 2018 [cited 2019 Dec 15]; 9(3): 2361-8. DOI: http://dx.doi.org/10.15649/cuidarte.v9i3.544.

28. Souza VD, Cortez EA, Carmo TGD. Educational measures to minimize occupational hazards in the ICU nursing staff. Rev. pesqui. cuid. fundam. (Online). 2017 [cited 2019 Jun 26]; 9(2): 583-91. DOI: http://dx.doi.org/10.9789/2175-5361.2017.v9i2.583-591.

29. Rezende KCAD, Tipple AFV, Souza ACS, Siqueira KM, Alves SB, Salgado TA, Pereira MS. Risk of exposure to biological material at primary health care facilities. Rev. enferm. UERJ, 2016; [cited 2020 Apr 10]; 24(2):e6442. DOI: http://dx.doi.org/10.12957/reuerj.2016.6442.

30. Sousa AFL, Queiroz AAFLN, Oliveira LB, Moura MEB, Batista OMA, Andrade D. Social representations of biosecurity in nursing: occupational health and preventive care. Rev. bras. enferm. (Online). 2016 [cited 2019 Jun 15]; 69(5): 864-71. DOI: http://dx.doi.org/10.1590/0034-7167-2015-0114. 